\title{
A Novel Microalgae Harvesting Method Using Laser Micromachined Glass Fiber Reinforced Polymers
}

\author{
Konstantina Tourlouki ${ }^{1}$, Vasiliki Tsavatopoulou ${ }^{2}$, Dimitris Alexandropoulos ${ }^{1, *}$, \\ Ioannis D. Manariotis $^{2}{ }^{(D}$ and Simone Mazzucato ${ }^{3}$ \\ 1 Department of Materials Science, University of Patras, 26504 Rio Patras, Greece; ktourlouki@upnet.gr \\ 2 Environmental Engineering Laboratory, Department of Civil Engineering, University of Patras, \\ 26504 Rio Patras, Greece; vasoutsav@gmail.com (V.T.); idman@upatras.gr (I.D.M.) \\ 3 SISMA S.p.A., via dell'Industria 1, 36013 Piovene Rocchette (VI), Italy; smazzucato@sisma.com \\ * Correspondence: dalexa@upatras.gr
}

Received: 6 March 2020; Accepted: 10 June 2020; Published: 15 June 2020

\begin{abstract}
Microalgae are an ideal source for next-generation biofuels due to their high photosynthetic rate. However, a key process limitation in microalgal biofuel production is harvesting of biomass and extraction of lipids in a cost-effective manner. The harvesting of the algal biomass amounts to approximately 20 to $30 \%$ of the total cost of the cultivation; hence, developing an efficient and universal harvesting method will make the commercialization of microalgal bio-cultures sustainable. In this study, we developed, demonstrated, and evaluated a novel harvesting method based on Glass Reinforced Fiber Polymer (GFRP) panels, suitable for industrial-scale installations. The proposed method was based on previous observations of preferential micro-algae development on glass surfaces, as well as in the assumption that the microalgae cells would prefer to attach to and grow on substrates with a similar size as them. At first, we developed a laser micromachining protocol for removing the resin and revealing the glass fibers of the GFRP, available for algal adhesion, thus acting as a microalgae biomass harvesting center. Surface micromachining was realized using a ns pulsed ultraviolet laser emitting at $355 \mathrm{~nm}$. This laser ensured high machining quality of the GFRP, because of its selective material ablation, precise energy deposition, and narrow heat affected zone. A specially built open pond system was used for the cultivation of the microalgae species Scenedesmus rubescens, which was suitable for biofuel production. The cultivation was used for the experimental evaluation of the proposed harvesting method. The cultivation duration was set to 16 days in order for the culture to operate at the exponential growth phase. The biomass maximum recovery due to microalgae attachment on the GFRP surface was $13.54 \mathrm{~g} / \mathrm{m}^{2}$, a yield comparable to other studies in the literature. Furthermore, the GFRP surfaces could be upscaled to industrial dimensions and positioned in any geometry dictated by the photobioreactor design. In this study, the glass fiber reinforced polymer used was suitable for the adhesion of Scenedesmus rubescens due to its fiber thickness. Other microalgae species could be cultivated, adhere, and harvested using GFRP of different fiber sizes and/or with a modified laser treatment. These very encouraging results validated GFRPs' harvesting capabilities as an attachment substrate for microalgae. Additional studies with more algae species will further strengthen the method.
\end{abstract}

Keywords: microalgae; harvesting; biofilm; GFRP; UV ns laser

\section{Introduction}

Microalgae biomass can be used for the production of a plethora of commercial products ranging from human food supplements, fish and animal feed, cosmetics and pharmaceutical products to alternative energy resources like biodiesel, bioethanol, biogas, and biohydrogen [1]. Indeed, biodiesel 
production from microalgae has attracted much attention due to its close similarity to conventional fossil diesel in terms of physical properties, energy content, and chemical structure. Apart from that, biodiesel is considered as a clean burning fuel with a low pour point and viscosity, and in addition, it is nontoxic, biodegradable, and eco-friendly, due to its relatively low emissions of sulfur dioxide $\left(\mathrm{SO}_{2}\right)$ [2-4]. Usually, biodiesel is blended with petro-diesel in various ratios and can be used in any diesel engine [5]. Biodiesel's production from microalgae is expected to be 15 to 300 times higher compared to conventional crop plants, which are usually harvested once or twice per year. On the other hand, microalgae's harvesting cycle is very short (around 14 days, depending on the species and cultivation method), which allows continuous harvesting throughout the year $[5,6]$. Among the numerous types of available algae suitable for biofuel production, in this specific work, Scenedesmus rubescens was selected due to its presence in freshwater and wastewater and its potential for biofuel production [6-8]. On the downside, the small size and density, 5.6-5.8 $\mu \mathrm{m}$ for Scenedesmus rubescens [9], make microalgae difficult to harvest $[10,11]$. Efficient, low-cost harvesting of microalgae's biomass is a major challenge for the commercialization of microalgal bio-cultures, as it amounts to approximately 20 to $30 \%$ of the total cost of cultivation [12-15]. Hence, there is an imperative need for developing an efficient and universal harvesting method that will improve the techno-economics of microalgae biofuel production. This is reflected in a wide range of microalgae harvesting methods already developed, which include centrifugation, flocculation, magnetic separation, and coagulation [16]. Centrifugation is effective for large-scale processes (80-90\% recovery [17]), but the capital cost is high. Chemical flocculation demands low energy, but the recovery of flocculants is difficult [18]. In flocculation, inorganic salts are used in high doses, decreasing the percentage of lipids or fatty acids in harvested cells [11]. In magnetic separation, the magnetic particles need to fulfil requirements such as: reusability, chemical stability, etc. [11]. Coagulation is a simple and fast method, but the chemical flocculants are expensive and toxic to the microalgal biomass [13]. The main disadvantages of these techniques are the increased overall operational costs ( 0.5 to $2 € / \mathrm{kg}$ dry weight algae), the high energy demand (ranging from 0.2 to $5 \mathrm{kWh} / \mathrm{kg}$ ), and the fact that they are less environmentally friendly [10,15]. Algal biofilm cultures can be used to minimize the high cost associated with algal harvesting. The algal adhesion is a complex process and is affected by various factors such as surface texture, micropattern, surface tension, and hydrophobicity [19-21]. Up to now, the exact role of the parameters affecting the algal adhesion is still not clear.

The scope of the contribution at hand is to demonstrate a novel harvesting method based on GFRP panels suitable for industrial-scale installations that surpasses the limitations of previously developed methods. Composites are reinforced materials that exhibit enhanced properties, e.g., mechanical strength, reduced weight, corrosion resistance, and flexibility. They consist of a matrix with reinforcing components, which can be fibers, laminates, or particles. Carbon fiber reinforced polymers (CFRPs), GFRPs, and fiber metal laminates (FMLs) are the most commonly used composites in industries [13,22]. GFRP is widely used in aerospace as a light aircraft construction material, as well as in the marine industry. The present work benefits from the massive technical know-how on the material aspects of GFRP developed over the years driven by the aforementioned applications.

The proposed method is inspired by honey harvesting in honey-bee combs: a GFRP is processed by laser to reveal the glass fiber network. Microalgae show a preference for developing on microporous surfaces [23], and hence, a mesh glass fiber (with diameters of approximately $10 \mu \mathrm{m}$ ) is an ideal substrate for the cultivation of microalgae. Then, the microalgae can be harvested from the GFRP using a blade. The foremost advantage of our method is its simplicity in implementation. It is easily envisaged that the laser machined GFRP panels can be upscaled to the appropriate dimensions. Additionally, the use of GFRP panels as cultivation surfaces is compatible with vertical bioreactors [24-26] used for the maximization of microalgae productivity. 


\section{Methods}

\subsection{Materials}

A commercially available bidirectional glass fiber reinforced polymer sheet was used. The dimensions were $30 \mathrm{~mm} \times 15 \mathrm{~mm}$ and a thickness of $2 \mathrm{~mm}$. The resin matrix was removed from the surface using laser micromachining protocols using a UV laser, revealing the glass fibers. The porous and rough structure of the fiber network favored the initial adhesion [17] of microalgae, thus acting as microalgae attachment centers. Additionally, glass fibers are transparent to light, thus facilitating the initiation of the cultivation process, which was critical for the overall system productivity [27].

\subsection{UV Laser Micromachining}

The microalgae adhesion properties were determined by the surface porosity, roughness, and hydrophilic properties [17]. Here, we employed a UV laser to modify these by laser micromachining of the surface of GFRP samples. The experiments were performed using a $15 \mathrm{~W}$ Q-switched UV laser emitting at $355 \mathrm{~nm}$ and operating in the ns regime. The UV laser workstation was comprised of a galvo mirror scanner and an F160 mm f-theta lens. The proper choice of delivering and focusing optics ensured a spot size of less than $20 \mu \mathrm{m}$ in diameter, at the sample surface.

The UV laser ensured high machining quality of fiber reinforced polymer composites by suppression of the polymer burn out [28]. The thermal effects exerted on the piece were minimized, resulting in a precise energy deposition and much narrower heat affected zone (HAZ). Especially for our case, where we wished to remove the resin and leave the glass fiber network intact, the use of a UV laser was ideal since the glass fibers of the composite were transparent to the UV laser beam, and therefore, the UV laser radiation would be completely absorbed by the resin [29]. Overall, UV laser processing of GFRP could provide a more clean-cut material removal. The UV laser micromachined GFRP samples are shown in Figure 1. It was evident that while resin was removed, revealing the glass fiber network, there was no obvious fiber breakage apart from some fiber discontinuities, which may be due to the material itself. The glass fiber thickness was $10.23 \mu \mathrm{m}$, comparable to the microalgae Scenedesmus rubescens' cell size.

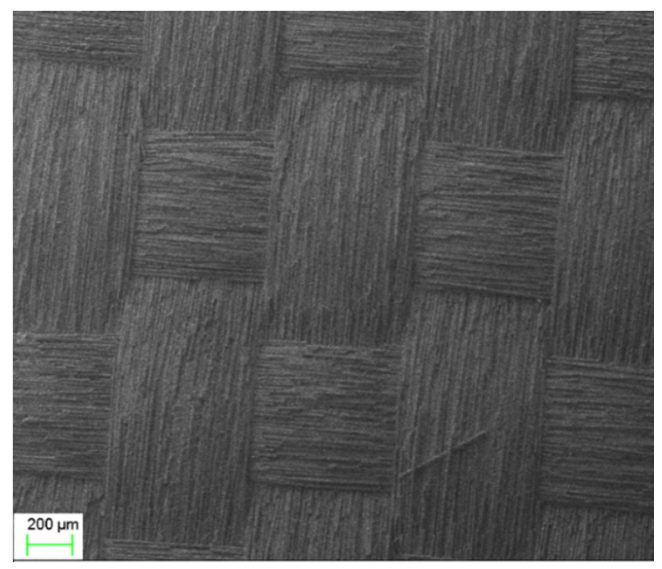

(a)

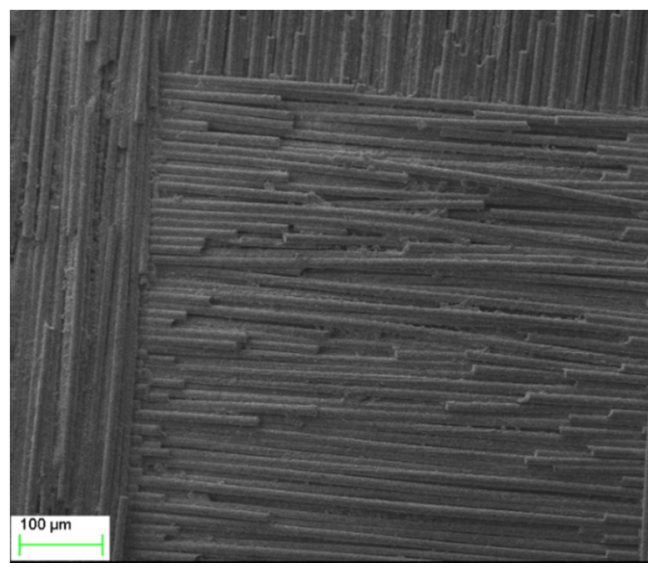

(b)

Figure 1. Cont. 


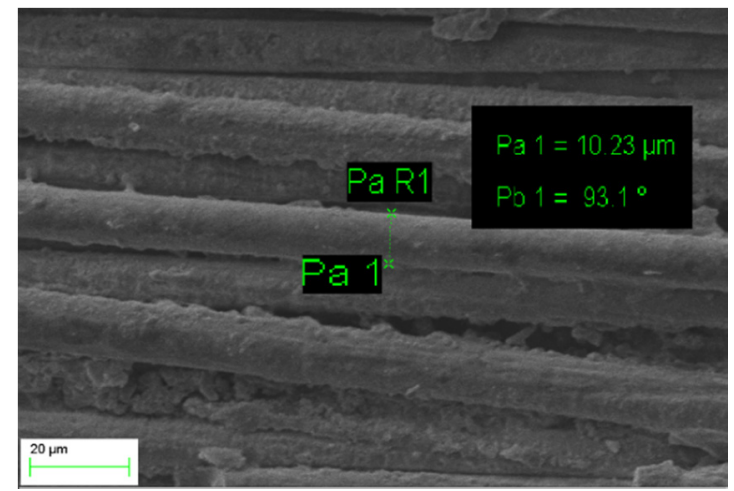

(c)

Figure 1. Scanning electron microscopy (SEM) image: (a) GFRP area after UV laser micromachining. The resin was removed, revealing the inner glass fiber mesh (magnification $84 \times$ ). (b) Larger magnification of the same area (magnification 306×). (c) Glass fiber thickness measurement: $10.23 \mu \mathrm{m}$ (magnification $2.09 \mathrm{~K} \times)$.

\subsection{Algal Cultivation}

Scenedesmus rubescens was obtained from the bank SAG Culture Collection of the University of Göttingen (SAG), and was cultivated in an open pond system, consisting of three rectangular reactor vessels (each of dimensions $26.5 \times 18.4 \times 4.5 \mathrm{~cm}^{3}(\mathrm{~L} \times \mathrm{W} \times \mathrm{H})$ ). All the UV laser micromachined materials were cut into rectangular coupons (each one $3.0 \times 1.5 \times 0.2 \mathrm{~cm}^{3}(\mathrm{~L} \times \mathrm{W} \times \mathrm{H})$ ) (Figure 2). The coupons were rinsed with deionized water and placed into the oven at $44^{\circ} \mathrm{C}$ for two days, and each coupon was weighted. After the 16 day algal cultivation, the samples with the biofilm created on their surface were removed and dried in the oven at $44^{\circ} \mathrm{C}$ for two days, and the mass was again measured. The algal precultures were prepared with $5 \mathrm{~L}$ of modified 1/3 N BG-11 medium (Blue Green-11 supplemented with one third times the nitrates concentration) in a glass bottle, which simulated freshwater. The bottle was illuminated by fluorescent lights providing illumination of $22 \mu \mathrm{mol} / \mathrm{m}^{2} / \mathrm{s}$ (LightScout, Quantum Meter, Model 341F, Spectrum Technologies, Inc., Aurora, IL, USA) and was placed in a walk-in incubator room under controlled environmental conditions at $20^{\circ} \mathrm{C}$. The algal culture was prepared from the preculture by appropriate dilution with 1/3 N BG-11 medium, resulting in a total suspended concentration of $164 \mathrm{mg} / \mathrm{L}$. A volume of $1 \mathrm{~L}$ of this suspension was then transferred into the reactors and recirculated at a flow rate of $2 \mathrm{~mL} / \mathrm{min}$ using a peristaltic pump (Masterflex L/S 7519-85, Cole Pamer Instrument, Co., Vernon hills, IL, USA). Two 36 W fluorescent lamps (cool daylight, length: $1.20 \mathrm{~m}$, and diameter: $2.5 \mathrm{~cm}$ ) were placed $30 \mathrm{~cm}$ above the culture's surface, providing illumination of $150 \mu \mathrm{mol} / \mathrm{m}^{2} / \mathrm{s}$. The coupons were removed after a period of 16 days from the reactors using tongs and rinsed by gently shaking on the spot. The period of 16 days was selected in order for the culture to operate at the exponential growth phase [6].

The microalgal suspended biomass was determined by the measurement of total suspended solids according to standard methods [30], and the free algal cell number was measured with a Neubauer hemocytometer (Optic Labor, Germany) after algae staining with Lugol's solution in order to separate the dead from live algae. The attached biomass was determined by the difference of the coupons' dry mass at each time compared to the mass of the coupons at Time 0 . The algal biofilm productivity was calculated by the following equation:

$$
\text { Algal biofilm productivity }\left(\mathrm{g} / \mathrm{m}^{2}\right)=\left(\mathrm{M}_{\mathrm{t}}-\mathrm{M}_{0}\right) / \mathrm{A}_{\mathrm{s}}
$$

where $\mathrm{M}_{\mathrm{t}}$ and $\mathrm{M}_{0}$ are the dried mass of the tested coupons harvested at time $\mathrm{t}$ (days) and before cultivation, respectively, and $A_{s}\left(m^{2}\right)$ is the surface of each tested coupon. 


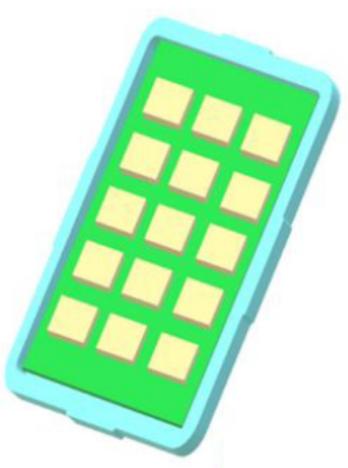

Plastic contaner

Microalgae

Laser micromachined GFRP
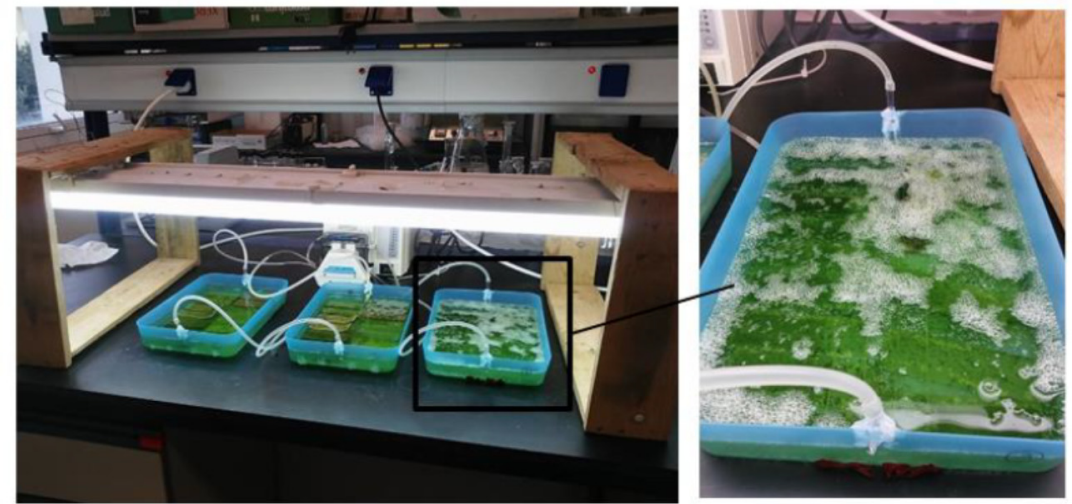

Figure 2. Schematic diagram and picture of the Scenedesmus rubescens microalgae cultivation system.

\section{Results and Discussion}

Figure 3 shows the macroscopic pictures of the micromachined GFRP surface with UV, before and after cultivation. The intact fiber mesh (Figure 3a) was fully covered with the algae mass (Figure 3b) already after four days of cultivation.

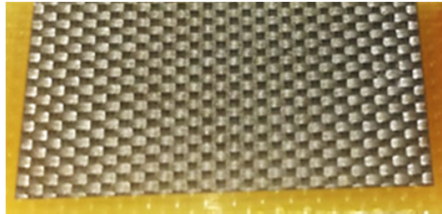

(a)

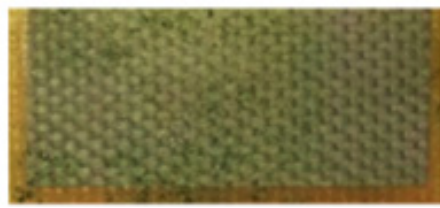

(b)

Figure 3. GFRP surface micromachined with a UV laser (a) before cultivation and (b) after four days of cultivation. The latter shows the microalgae's complete adhesion and coverage of the laser patterned area.

The growth of suspended algal biomass in the reactors was monitored by measuring the number of cells. As shown in Figure 4a, after a lag phase of four days, it started to increase until reaching a value of $3.14 \times 10^{7}$ cells $/ \mathrm{mL}$. The GFRP surfaces were collected from the cultivation system, having a microalgae biofilm formed on the surface. The mass of the GFRP after the algal biofilm formation on its surface was compared to the initial mass of the GFRP materials, before cultivation. Consequently, the mass change was equal to the algal biomass on top of the composite. The evolution of the measured algae biomass with days of cultivation is shown in Figure $4 \mathrm{~b}$. It is interesting to note that there was a linear dependence of microalgae mass with time of cultivation, indicating that the potential of microalgae cultivation was not exhausted since there were no signs of growth saturation for the time span under study. For the 16 day cultivation, the maximum biomass recovery from the UV laser micromachined GFRP was $13.54 \mathrm{~g} / \mathrm{m}^{2}$, corresponding to $0.84 \mathrm{~g} / \mathrm{m}^{2} / \mathrm{d}$. In the literature, algal biofilm productivities reach values up to $6.3 \mathrm{~g} / \mathrm{m}^{2} / \mathrm{d}$ depending on the reactor type and the substrate used [26].

In Table 1, the results of the time evolution of our experiments are shown. In the same table, we include the pictures of the recovered GFRP coupons for progressive days of cultivation. As shown, microalgae were selective and preferred to better adhere on the modified part of the surface rather than the untreated frame. This trend was quite obvious up to the first 12 days of cultivation; at the $16^{\text {th }}$ day, there was an indication of algal growth spreading on the untreated surface. Noticeably, after 16 days of cultivation, microalgae started to cover, apart from the glass mesh, also the untreated resin. It was anticipated that these very promising results could be further improved if the roughness of 
the glass fiber mesh could be enhanced. Then, fiber mesh discontinuities, e.g., in the form of broken fibers, would act as anchor points for the microalgae organisms, resulting in thicker biofilm creation. This was not possible with UV laser treated GFRP because the UV radiation removed only the resin without affecting the glass fiber network. Using an IR fiber laser for GFRP micromachining could be an alternative method, as it ablates indistinctively both fibers and resin, modifying the substrate's surface texture completely. This is an ongoing experiment under our investigation.
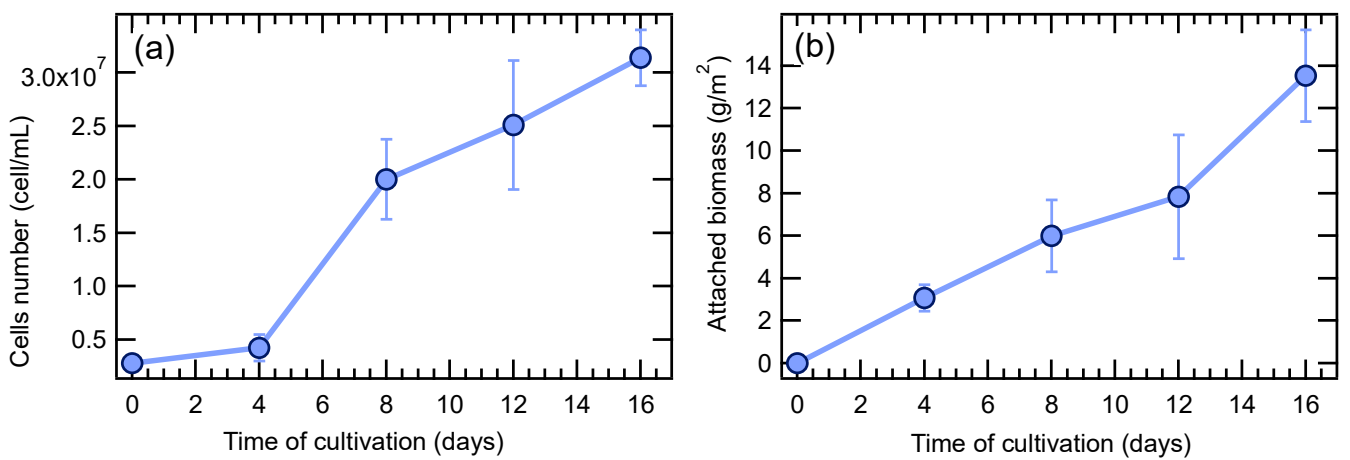

Figure 4. Algal biomass during cultivation: (a) suspended biomass and (b) attached algal biomass on UV micromachined GFRP. Error bars are shown as standard deviations: $n=3$ for (a) and $n=2$ for (b).

An added advantage of our method was that, apart from the very good biomass adhesion on the laser microstructured GFRP surfaces, these could be positioned in any geometry dictated by the photobioreactor design, including the vertical positioning in a cultivation pond for maximum light utilization and thus maximum algae colonization [31]. The GFRP surfaces could be reused as harvesting centers after the removal of the attached algal biomass, thus contributing to the overall biomass harvesting cost reduction. Apparently, further research is required with more algae species and mixed cultures in order to investigate the effectiveness of the process.

Table 1. Algae biomass adhesion on UV laser micromachined GFRP over time. The table includes the mean value of the algal biomass that attached on two replicate GFRP coupons.

\begin{tabular}{|c|c|c|}
\hline Time of Cultivation (Days) & Algae Biomass $\left(\mathrm{g} / \mathrm{m}^{2}\right)$ & UV Micromachined GFRP \\
\hline 0 & 0 & \\
\hline 4 & 3.08 & \\
\hline 8 & 6.00 & \\
\hline 12 & 7.84 & \\
\hline 16 & 13.54 & \\
\hline
\end{tabular}

\section{Conclusions}

We developed a novel microalgae harvesting procedure aiming at maximizing the overall biomass recovery at lower cost that was based on UV laser micromachined GFRP. Scenedesmus rubescens, 
which offered a cell size comparable to the glass fiber thickness, was used as a first-study cultivation species. This was the first demonstration to our knowledge of a microalgae harvesting technique that was based on low-cost surface processed composite materials. Our method was based on the observation that microalgae tended to grow on microporous surfaces, and hence, this should apply for the mesh glass fiber of GFRP. Indeed, it was shown that processing of GFRP surfaces with UV laser radiation revealed the fiber mesh network that was suitable for microalgae colonization and harvesting. Our harvesting technique's yield for a 16 day microalgae cultivation was $13.54 \mathrm{~g} / \mathrm{m}^{2}$, comparable to state-of-the-art, yet more expensive microalgae harvesting methods. This first study aimed at demonstrating the proof of concept and not at recovering the highest algal biomass value.

The resulting GFRP laser processed surfaces contributed to the overall optimization of algal adhesion and could be of any shape and size, providing flexibility and scalability. The GFRP harvesting plates were reusable, as they could be cleaned by an elementary heat treatment without material degradation, further improving the technoeconomic criteria of the microalgae bioreactor system. The results presented here served the purpose of demonstrating the potential of the technique; hence, it is anticipated that optimization of the method in future work will result in improved biomass recovery values comparable with other more complex and costly methods.

Author Contributions: Conceptualization by D.A. and I.D.M.; methodology by D.A., I.D.M. and S.M.; investigation by K.T., V.T., D.A., I.D.M.; writing and project administration by K.T., V.T., D.A., I.D.M., S.M. All authors have read and agreed to the published version of the manuscript.

Funding: This research received no external funding.

Acknowledgments: SISMA S.p.A. is acknowledged for the provision of the laser system and contribution throughout the experimental procedure.

Conflicts of Interest: The authors declare no conflict of interest.

\section{References}

1. Hattab, M.A. Microalgae Harvesting Methods for Industrial Production of Biodiesel: Critical Review and Comparative Analysis. J. Fundam. Renew. Energy Appl. 2015, 5. [CrossRef]

2. Mirhashemi, F.S.; Sadrnia, H. NOX emissions of compression ignition engines fueled with various biodiesel blends: A review. J. Energy Inst. 2020, 93, 129-151. [CrossRef]

3. Dincer, K. Lower Emissions from Biodiesel Combustion. Energy Sources Part A Recover. Util. Environ. Eff. 2008, 30, 963-968. [CrossRef]

4. Tsavatopoulou, V.D.; Aravantinou, A.F.; Manariotis, I.D. Biofuel conversion of Chlorococcum sp. and Scenedesmus sp. biomass by one- and two-step transesterification. Biomass Convers. Biorefinery. 2019. [CrossRef]

5. Kadir, W.N.A.; Lam, M.K.; Uemura, Y.; Lim, J.W.; Lee, K.T. Harvesting and pre-treatment of microalgae cultivated in wastewater for biodiesel production: A review. Energy Convers. Manag. 2018, 171, 1416-1429. [CrossRef]

6. Aravantinou, A.F.; Theodorakopoulos, M.A.; Manariotis, I.D. Selection of microalgae for wastewater treatment and potential lipids production. Bioresour. Technol. 2013, 147, 130-134. [CrossRef]

7. Tsavatopoulou, V.D.; Vakros, J.; Manariotis, I.D. Lipid conversion of Scenedesmus rubescens biomass into biodiesel using biochar catalysts from malt spent rootlets. J. Chem. Technol. Biotechnol. 2020. [CrossRef]

8. Lv, J.; Guo, B.; Feng, J.; Liu, Q.; Nan, F.; Liu, X.; Xie, S. Integration of wastewater treatment and flocculation for harvesting biomass for lipid production by a newly isolated self-flocculating microalga Scenedesmus rubescens SX. J. Clean. Prod. 2019, 240, 118211. [CrossRef]

9. Kumar, L.; Roy, A.; Saxena, G.; Kundu, K.; Bharadvaja, N. Isolation, Identification and biomass productivity analysis of microalga Scenedesmus rubescens from DTU Lake. J. Algal Biomass Util. 2017, 8, 56-67.

10. Rinanti, A.; Purwadi, R. Harvesting of freshwater microalgae biomass by Scenedesmus sp. as bioflocculant. IOP Conf. Ser. Earth Environ. Sci. 2018, 106, 012087. [CrossRef]

11. Vergini, S.; Aravantinou, A.F.; Manariotis, I.D. Harvesting of freshwater and marine microalgae by common flocculants and magnetic microparticles. J. Appl. Phycol. 2016, 28, 1041-1049. [CrossRef]

12. Molina Grima, E.; Belarbi, E.-H.; Acién Fernández, F.G.; Robles Medina, A.; Chisti, Y. Recovery of microalgal biomass and metabolites: Process options and economics. Biotechnol. Adv. 2003, 20, 491-515. [CrossRef] 
13. Barros, A.I.; Gonçalves, A.L.; Simões, M.; Pires, J.C.M. Harvesting techniques applied to microalgae: A review. Renew. Sustain. Energy Rev. 2015, 41, 1489-1500. [CrossRef]

14. Brennan, L.; Owende, P. Biofuels from microalgae-A review of technologies for production, processing, and extractions of biofuels and co-products. Renew. Sustain. Energy Rev. 2010, 14, 557-577. [CrossRef]

15. Fasaei, F.; Bitter, J.H.; Slegers, P.M.; van Boxtel, A.J.B. Techno-economic evaluation of microalgae harvesting and dewatering systems. Algal Res. 2018, 31, 347-362. [CrossRef]

16. Carbone, D.A.; Gargano, I.; Pinto, G.; De Natale, A.; Pollio, A. Evaluating microalgal attachment to surfaces: A first approach towards a laboratory integrated assessment. Chem. Eng. Trans. 2017, 57, 73-78. [CrossRef]

17. Chen, C.-Y.; Yeh, K.-L.; Aisyah, R.; Lee, D.-J.; Chang, J.-S. Cultivation, photobioreactor design and harvesting of microalgae for biodiesel production: A critical review. Bioresour. Technol. 2011, 102, 71-81. [CrossRef]

18. Beach, E.S.; Eckelman, M.J.; Cui, Z.; Brentner, L.; Zimmerman, J.B. Preferential technological and life cycle environmental performance of chitosan flocculation for harvesting of the green algae Neochloris oleoabundans. Bioresour. Technol. 2012, 121, 445-449. [CrossRef]

19. Wang, J.-H.; Zhuang, L.-L.; Xu, X.-Q.; Deantes-Espinosa, V.M.; Wang, X.-X.; Hu, H.-Y. Microalgal attachment and attached systems for biomass production and wastewater treatment. Renew. Sustain. Energy Rev. 2018, 92, 331-342. [CrossRef]

20. Roostaei, J.; Zhang, Y.; Gopalakrishnan, K.; Ochocki, A.J. Mixotrophic Microalgae Biofilm: A Novel Algae Cultivation Strategy for Improved Productivity and Cost-efficiency of Biofuel Feedstock Production. Sci. Rep. 2018, 8, 12528. [CrossRef]

21. Zhang, Q.; Yu, Z.; Zhu, L.; Ye, T.; Zuo, J.; Li, X.; Xiao, B.; Jin, S. Vertical-algal-biofilm enhanced raceway pond for cost-effective wastewater treatment and value-added products production. Water Res. 2018, 139, 144-157. [CrossRef]

22. Thakur, P.; Teli, S.N.; Lad, S. Multiobjective Optimization in Drilling of Composites. In Proceedings of the International Conference on Intelligent Manufacturing and Automation, Wuhan, China, 16-18 October 2020; Vasudevan, H., Kottur, V.K.N., Raina, A.A., Eds.; Springer: Singapore, 2019; pp. 279-286; ISBN 9789811324895.

23. Podola, B.; Li, T.; Melkonian, M. Porous Substrate Bioreactors: A Paradigm Shift in Microalgal Biotechnology? Trends Biotechnol. 2017, 35, 121-132. [CrossRef]

24. Lien, N.T. The Cultivation of Spirulina Platensis on Vertical Aeroponic Substrates. JST 2018, 54, 307. [CrossRef]

25. Altman, A.; Colwell, R.R. Agricultural Biotechnology; Books in Soils, Plants, and the Environment; Marcel Dekker: New York, NY, USA, 1998; ISBN 978-0-8247-9439-2.

26. Orfanos, A.G.; Manariotis, I.D. Algal biofilm ponds for polishing secondary effluent and resource recovery. J. Appl. Phycol. 2019, 31, 1765-1772. [CrossRef]

27. Sirmerova, M.; Prochazkova, G.; Siristova, L.; Kolska, Z.; Branyik, T. Adhesion of Chlorella vulgaris to solid surfaces, as mediated by physicochemical interactions. J. Appl. Phycol. 2013, 25, 1687-1695. [CrossRef]

28. Li, Z.L.; Zheng, H.Y.; Lim, G.C.; Chu, P.L.; Li, L. Study on UV laser machining quality of carbon fibre reinforced composites. Compos. Part A Appl. Sci. Manuf. 2010, 41, 1403-1408. [CrossRef]

29. Takahashi, K.; Tsukamoto, M.; Masuno, S.; Sato, Y. Heat conduction analysis of laser CFRP processing with IR and UV laser light. Compos. Part A Appl. Sci. Manuf. 2016, 84, 114-122. [CrossRef]

30. Rice, E.W. (Ed.) Standard Methods for the Examination of Water and Wastewater, 22th ed.; American Public Health Association: Washington, DC, USA, 2012; ISBN 978-0-87553-013-0.

31. Wang, S.-K.; Stiles, A.R.; Guo, C.; Liu, C.-Z. Microalgae cultivation in photobioreactors: An overview of light characteristics. Eng. Life Sci. 2014, 14, 550-559. [CrossRef]

(C) 2020 by the authors. Licensee MDPI, Basel, Switzerland. This article is an open access article distributed under the terms and conditions of the Creative Commons Attribution (CC BY) license (http://creativecommons.org/licenses/by/4.0/). 